\title{
Shielded Metal Arc Welding Electrode Selection Using Technique for Order Preference by Similarity to Ideal Solution (TOPSIS) Method
}

\author{
R. Bansode $^{1 *}$, S. Gangurde ${ }^{2}$ \\ ${ }^{1}$ PG Student, K.K Wagh Institute of Engineering Education and Research, Nasik, India \\ ${ }^{2}$ Associate Professor, K.K Wagh Institute of Engineering Education and Research, Nasik, India \\ \{rjfrncs01@gmail.com\}
}

\begin{abstract}
An important factor in welding process is selection of appropriate welding electrode. If a wrong welding electrode is selected then it may give rise to various welding defects and ultimately lead to failure of weld.In this paper, best welding electrode is selected from available alternatives of general purpose electrodes for mild steel for Shielded Metal Arc Welding process (SMAW). The selection is done by using Technique for Order Preference by Similarity to Ideal Solution (TOPSIS) method. The results are then compared with other Multi Attribute Decision Making (MADM) methods; Simple Additive Weighing (SAW), Weighted Product Method (WPM), Modified TOPSIS. The best ranked electrode by all the methods is then selected as the best welding electrode from available alternatives.
\end{abstract}

Keywords: Shielded Metal Arc Welding, welding electrodes, TOPSIS

\section{Introduction}

Shielded metal arc welding (SMAW), also known as stick welding, is a process in which the joining occurs by melting the electrode by the arc established between a sticklike covered electrode and the metals [1]. There are many electrodes available for SMAW process. Each welding electrode comes with a set of parameters on the material of electrode and the diameter of electrode. This makes it very important to select appropriate electrode for welding process. If the appropriate electrode for the welding operation is not selected then it may give rise to various defects viz. undercutting, porosity, incomplete penetration, incomplete fusion, longitudinal cracking, spatter and arc instability [2]. This problem of selecting the appropriate electrode is solved by using multi attribute decision making (MADM) methods. Technique for Order Preference by Similarity to Ideal Solution (TOPSIS) Method is one of the MADM methods which is widely used. The results of TOPSIS are then compared with other MADM methods like Simple Additive Weighing (SAW) Method, Weighted Product Method (WPM) and Modified TOPSIS. In this work, six different alternatives are considered for general purpose welding of mild steel for SMAW. These electrodes are evaluated on the basis of seven criteria such as tensile strength (TS), yield strength (YS), elongation (E), reduction in area (RA), Charpy V-Notch impact test $(\mathrm{CVN})$, deposition rate (DR), cost.

\section{Methodology}

The initial step for the methodology (Fig. 1) is to prepare the decision matrix. To prepare the decision matrix we have to identify the alternatives, criteria and calculate the weights of the criteria. Then we compare each electrode on different criteria (performance measures). The ranking of the criteria is done on the basis of the performance index calculated by the MADM methods.

The decision matrix for the problem is shown in Table 1. All the criteria, except for cost, are beneficial. There are six alternative selected for the problem. The weights of the criteria are calculated by Analytical Hierarchy Process (AHP) [3]. The elements of the decision table are to be normalized; as the criteria have different units,

B. Iyer, S. Nalbalwar and R. Pawade (Eds.)

ICCASP/ICMMD-2016. Advances in Intelligent Systems Research.

Vol. 137, Pp. 15-20.

(C) 2017. The authors - Published by Atlantis Press

This is an open access article under the CC BY-NC license (http://creativecommons.org/licens)es/by-nc/4.0/).

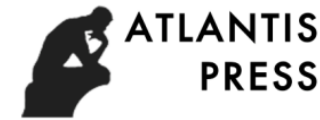


so that all the possible attributes in the decision problem can be considered.The values of criteria were taken from the product catalogue of a leading welding electrode manufacturer ESAB.

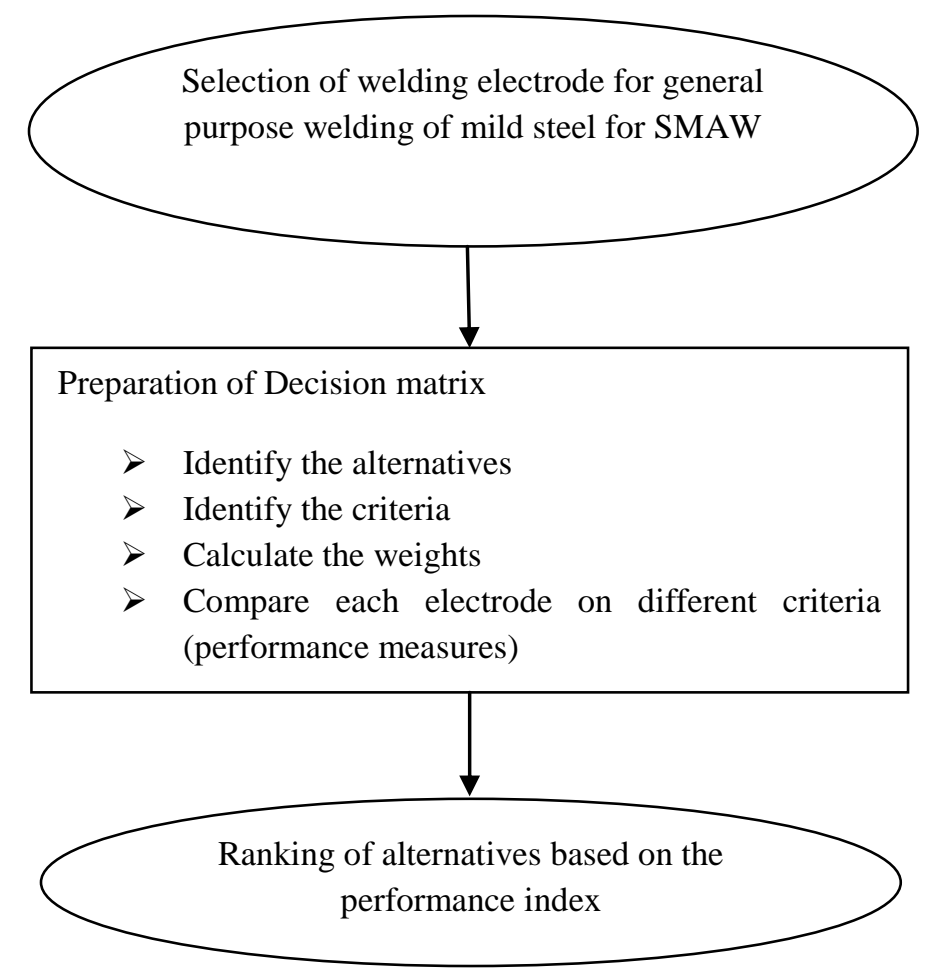

Fig. 1. Methodology

Table 1 Decision matrix

\begin{tabular}{|c|c|c|c|c|c|c|c|}
\hline Alternatives & \multicolumn{9}{|c|}{ Criteria } \\
\hline & $\begin{array}{c}\text { TS } \\
(\mathbf{M P a})\end{array}$ & $\begin{array}{c}\text { YS } \\
(\mathbf{M P a})\end{array}$ & $\begin{array}{c}\mathbf{E} \\
(\boldsymbol{\%})\end{array}$ & $\begin{array}{c}\text { RA } \\
(\boldsymbol{\%})\end{array}$ & $\begin{array}{c}\text { CVN } \\
(\mathbf{J})\end{array}$ & DR (kg/hr) & $\begin{array}{c}\text { Cost } \\
(\mathbf{₹})\end{array}$ \\
\hline Weights & $\mathbf{0 . 1 6}$ & $\mathbf{0 . 0 7}$ & $\mathbf{0 . 1 5}$ & $\mathbf{0 . 1 8}$ & $\mathbf{0 . 0 6}$ & $\mathbf{0 . 2 5}$ & $\mathbf{0 . 1 4}$ \\
\hline E6010 & 427 & 490 & 28 & 65 & 37 & 1.40 & 369.36 \\
\hline E6011 & 562 & 524 & 22 & 56 & 50 & 1.70 & 254.28 \\
\hline E6013 & 482 & 558 & 27 & 55 & 47 & 1.45 & 294.42 \\
\hline E7010-P1 & 480 & 560 & 22 & 56 & 39 & 1.30 & 397.48 \\
\hline E7014 & 420 & 490 & 28 & 64 & 60 & 1.70 & 262.30 \\
\hline E7024 & 490 & 550 & 26 & 63 & 34 & 3.30 & 262.30 \\
\hline
\end{tabular}

\subsection{Technique for Order Preference by Similarity to Ideal Solution (TOPSIS) Method}

TOPSIS method was first proposed by Hwang and Yoon [4]. In this method, we choose the best alternative having the shortest distance to the ideal solution and the farthest distance from the negative-ideal solution. We calculate the normalized values $\left(\mathrm{R}_{\mathrm{ij}}\right)$ by Eq. (1).

$$
R_{i j}=\frac{y_{i j}}{\sqrt{\sum_{j=1}^{m} y_{i j}^{2}}}
$$


where, $\mathrm{y}_{\mathrm{ij}}$ are the performance measures of the criteria.

The quantitative values of the welding electrode selection attributes are normalized by Eq. (1) and are shown in Table 2.

Table 2 Normalized matrix for TOPSIS and modified TOPSIS

\begin{tabular}{|l|l|l|c|c|c|c|c|}
\hline \multirow{2}{*}{ Alternatives } & \multicolumn{7}{|c|}{ Criteria } \\
\cline { 2 - 8 } & TS & YS & E & RA & CVN & DR & Cost \\
\hline Weight & $\mathbf{0 . 1 6}$ & $\mathbf{0 . 0 7}$ & $\mathbf{0 . 1 5}$ & $\mathbf{0 . 1 8}$ & $\mathbf{0 . 0 6}$ & $\mathbf{0 . 2 5}$ & $\mathbf{0 . 1 4}$ \\
\hline E6010 & 0.3638 & 0.3778 & 0.4460 & 0.4424 & 0.3329 & 0.2957 & 0.4836 \\
\hline E6011 & 0.4789 & 0.4040 & 0.3504 & 0.3811 & 0.4498 & 0.3590 & 0.3329 \\
\hline E6013 & 0.4107 & 0.4302 & 0.4301 & 0.3743 & 0.4228 & 0.3062 & 0.3855 \\
\hline E7010-P1 & 0.4090 & 0.4318 & 0.3504 & 0.3811 & 0.3509 & 0.2745 & 0.5204 \\
\hline E7014 & 0.3579 & 0.3778 & 0.4460 & 0.4356 & 0.5398 & 0.3590 & 0.3434 \\
\hline E7024 & 0.4175 & 0.4241 & 0.4142 & 0.4288 & 0.3059 & 0.6969 & 0.3434 \\
\hline
\end{tabular}

Then the separation measures of each alternative are calculated using Eq. (2) and Eq. (3).

$S_{i}^{+}=\sqrt{\sum_{j=1}^{m}\left(V_{i j}-V_{j}^{+}\right)^{2}}$

$S_{i}^{-}=\sqrt{\sum_{j=1}^{m}\left(V_{i j}-V_{j}^{-}\right)^{2}}$

The separation measures calculated by Eq. (2) and Eq. (3) are given below.

$$
\begin{array}{ll}
\mathrm{S}_{1}{ }^{+}=0.1050 & \mathrm{~S}_{1}{ }^{-}=0.0203 \\
\mathrm{~S}_{2}{ }^{+}=0.0866 & \mathrm{~S}_{2}=0.0399 \\
\mathrm{~S}_{3}{ }^{+}=0.0996 & \mathrm{~S}_{3}=0.0264 \\
\mathrm{~S}_{4}{ }^{+}=0.1114 & \mathrm{~S}_{4}{ }^{-}=0.0095 \\
\mathrm{~S}_{5}{ }^{+}=0.0868 & \mathrm{~S}_{5}{ }^{-}=0.0389 \\
\mathrm{~S}_{6}{ }^{+}=0.0180 & \mathrm{~S}_{6}{ }^{-}=0.1098
\end{array}
$$

The composite or overall scores are termed as Electrode Selection Index (ESI), $\mathrm{P}_{\mathrm{i}}$ and are calculated by Eq. (4).

$$
P_{i}=\frac{S_{i}^{-}}{\left(S_{i}^{+}+S_{i}^{-}\right)}
$$

The overall scores $\left(\mathrm{P}_{\mathrm{i}}\right)$ are shown in Table 4 and the alternatives are ranked in descending order of their scores in Table 5.

\subsection{Modified TOPSIS}

This method was presented by Deng et al. [5]. In this method, the positive ideal solution and the negative ideal solution are not dependent on the weighted decision matrix. The normalized is same as that of calculated in TOPSIS and is shown in Table 2. Using Eq. (5) and Eq. (6) we calculate the weighted Euclidean distances. 


$$
D_{i}^{+}=\sqrt{\sum_{j=1}^{m} w_{j}\left(R_{i j}-R_{j}^{+}\right)^{2}}
$$

$$
D_{i}^{-}=\sqrt{\sum_{j=1}^{m} w_{j}\left(R_{i j}-R_{j}^{-}\right)^{2}}
$$

The values of weighted Euclidean distances are given below

$$
\begin{array}{ll}
\mathrm{D}_{1}{ }^{+}=0.2198 & \mathrm{D}_{1}{ }^{-}=0.0505 \\
\mathrm{D}_{2}{ }^{+}=0.1764 & \mathrm{D}_{2}{ }^{-}=0.1017 \\
\mathrm{D}_{3}{ }^{+}=0.2024 & \mathrm{D}_{3}{ }^{-}=0.0722 \\
\mathrm{D}_{4}{ }^{+}=0.2334 & \mathrm{D}_{4}{ }^{-}=0.0274 \\
\mathrm{D}_{5}{ }^{+}=0.1764 & \mathrm{D}_{5}{ }^{-}=0.1072 \\
\mathrm{D}_{6}{ }^{+}=0.0640 & \mathrm{D}_{6}{ }^{-}=0.2255
\end{array}
$$

The overall scores $\left(\mathrm{P}_{\mathrm{i}}\right)$ are calculated by Eq. (7) and is shown in Table 4 and the alternatives are ranked in descending order of their scores in Table 5.

$$
P_{i}=\frac{D_{i}^{-}}{\left(D_{i}^{+}+D_{i}^{-}\right)}
$$

\subsection{Simple Additive Weighing (SAW) Method}

This method was developed by Fishburn in 1967 [6] and is also called Weighted Sum Method. The decision matrix is normalized before calculating the overall scores.

$$
P_{i}=\sum_{j=1}^{m} w_{j}\left(y_{i j}\right)_{\text {normal }}
$$

Where $\left(\mathrm{z}_{\mathrm{ij}}\right)_{\text {normal }}$ is the normalized value of $\mathrm{z}_{\mathrm{ij}}$ i.e. normalized values of performance measures. The overall scores are calculated by Eq. (8). The alternative having the highest composite score $\mathrm{P}_{\mathrm{i}}$ is the best option from the given set of alternatives. The normalized matrix is shown in Table 3.

Table 3 Normalized matrix for SAW and WPM

\begin{tabular}{|l|c|c|c|c|c|c|c|}
\hline Alternatives & \multicolumn{9}{|c|}{ Criteria } \\
\hline & TS & YS & E & RA & CVN & DR & Cost \\
\hline Weights & $\mathbf{0 . 1 6}$ & $\mathbf{0 . 0 7}$ & $\mathbf{0 . 1 5}$ & $\mathbf{0 . 1 8}$ & $\mathbf{0 . 0 6}$ & $\mathbf{0 . 2 5}$ & $\mathbf{0 . 1 4}$ \\
\hline E6010 & 0.7598 & 0.8750 & 1.0000 & 1.0000 & 0.6167 & 0.4242 & 0.6884 \\
\hline E6011 & 1.0000 & 0.9357 & 0.7857 & 0.8615 & 0.8333 & 0.5152 & 1.0000 \\
\hline E6013 & 0.8577 & 0.9964 & 0.9643 & 0.8462 & 0.7833 & 0.4394 & 0.8637 \\
\hline E7010-P1 & 0.8541 & 1.0000 & 0.7857 & 0.8615 & 0.6500 & 0.3939 & 0.6397 \\
\hline E7014 & 0.7473 & 0.8750 & 1.0000 & 0.9846 & 1.0000 & 0.5152 & 0.9694 \\
\hline E7024 & 0.8719 & 0.9821 & 0.9286 & 0.9692 & 0.5667 & 1.0000 & 0.9694 \\
\hline
\end{tabular}

The ranking of alternatives is shown in Table 5.

\subsection{Weighted Product Method (WPM)}


This method is similar to SPM and was developed by Miller and Starr in1969 [7]. WPM uses multiplication instead of addition. The normalized matrix is same as that of calculated in SPM. The overall scores (ESI) is calculated by Eq. (9).

$$
P_{i}=\prod_{j=1}^{m}\left[\left(y_{i j}\right)_{n o r m a l}\right]^{w_{j}}
$$

The overall scores $\left(\mathrm{P}_{\mathrm{i}}\right)$ are shown in Table 4 and the ranking of alternatives is given in Table 5 .

\section{Results and Discussion}

The results of MADM methods applied for the selection of welding electrode for general purpose electrodes for mild steel for SMAW process is shown in Table 4.

Table 4 Electrode Selection Index (ESI)

\begin{tabular}{|l|l|l|l|l|}
\hline \multicolumn{5}{|c|}{ Electrode Selection Index (ESI) } \\
\hline & TOPSIS & $\begin{array}{c}\text { MOD. } \\
\text { TOPSIS }\end{array}$ & SAW & WPM \\
\hline E6010 & 0.1623 & 0.1870 & 0.7523 & 0.7054 \\
\hline E6011 & 0.3153 & 0.3657 & 0.8172 & 0.7832 \\
\hline E6013 & 0.2095 & 0.2629 & 0.7817 & 0.7400 \\
\hline E7010-P1 & 0.0784 & 0.1051 & 0.7066 & 0.6640 \\
\hline E7014 & 0.3145 & 0.3781 & 0.8326 & 0.7954 \\
\hline E7024 & 0.8590 & 0.7790 & 0.9417 & 0.9246 \\
\hline
\end{tabular}

Based upon the Electrode Selection Index (ESI), the alternatives are ranked as shown in Table 5.

Table 5 Ranking of electrodes

\begin{tabular}{|l|l|l|l|l|}
\hline \multicolumn{5}{|c|}{ Rankings } \\
\hline & TOPSIS & $\begin{array}{c}\text { MOD. } \\
\text { TOPSIS }\end{array}$ & SAW & WPM \\
\hline E6010 & 5 & 5 & 5 & 5 \\
\hline E6011 & 2 & 3 & 3 & 3 \\
\hline E6013 & 4 & 4 & 4 & 4 \\
\hline E7010-P1 & 6 & 6 & 6 & 6 \\
\hline E7014 & 3 & 2 & 2 & 2 \\
\hline E7024 & 1 & 1 & 1 & 1 \\
\hline
\end{tabular}

The results of TOPSIS are compared with other three MADM methods viz. modified TOPSIS, SPM and WPM. TOPSIS ranks electrode E7024 as the best electrode. This result is then compared to other methods. Modified TOPSIS, SPM and WPM also ranks electrode E7024 as the best electrode. Hence, from the rankings shown in Table 5, electrode E7024 is the best option from the available electrodes. 


\section{Conclusions}

In this paper, we identified the important criteria for selection of SMAW electrodes for general purpose welding of mild steel. TOPSIS method was applied for selection for of best alternative. The results of TOPSIS were then compared with Modified TOPSIS, SPM and WPM. The results by all the methods showed that electrode E7024 is the best welding electrode from the available set electrodes. A close look at the attributes of the alternatives will show that E7024 is having the highest deposition rate which is a very important criterion. Also, the cost of E7024 is quite lower when compared to other electrodes. Hence, we can say that the E7024 is the best electrode from the given set of alternatives.

\section{References}

[1]. S. Kou, Welding Metallurgy, second ed., John Wiley and Sons, New Jersey, 2003

[2]. MIG Welding handbook, ESAB Welding \&Cutting Products, ESAB North America

[3]. Saaty T.L. The Analytic Hierarchy Process, New York: McGraw Hill. International, Translated to Russian, Portuguese, and Chinese, Revised editions, Paperback (1996, 2000), Pittsburgh: RWS Publications (1980).

[4]. Saaty T.L. and Vargas, L.G. Models, Methods, Concepts and Applications of the Analytic Hierarchy Process, Boston: Kluwer Academic Publishers (2000).

[5]. Hwang C.L. and Yoon K., Multiple attribute decision making-methods and applications, SpringerVerlag, Heidelberg (1981).

[6]. Deng H., Yeh C.H. and Willis R.J., Inter-company comparison using modified TOPSIS with objective weights, Computers and Operation Research, Vol.27, pp. 963-973(2000).

[7]. Fishburn P.C., (1967), “Additive utilities with incomplete product set: applications to priorities and assignments", Operations Research Society of America, Baltimore.

[8]. Miller D. W. and Starr M.K., (1969), "Executive decisions with operations research", Prentice Hall, Englewood Cliffs, New Jersey. 